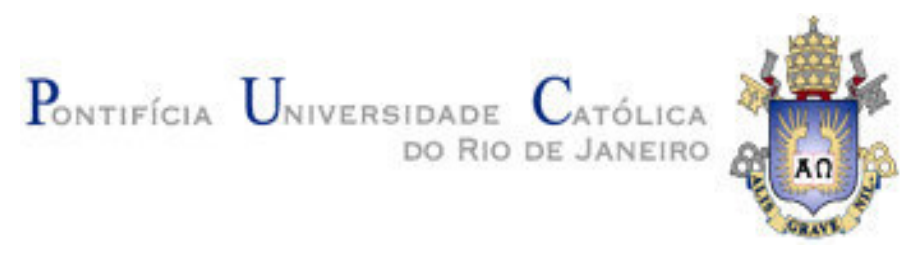

Sabrina Villenave

Keep Calm and Carry On: a instrumentalização da memória no Estado Moderno

Dissertação de Mestrado

Dissertação apresentada como requisito parcial para obtenção do grau de Mestre pelo Programa de Pósgraduação em Relações Internacionais do Instituto de Relações Internacionais da PUC-Rio.

Orientador: Prof. Paulo Luiz Lavigne Moreaux Esteves

Rio de Janeiro Outubro de 2011 


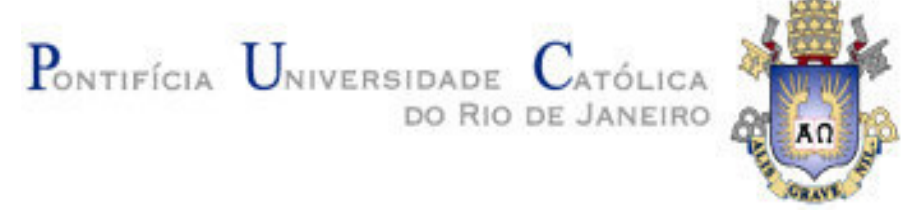

Sabrina Villenave

\section{Keep Calm and Carry On: \\ a instrumentalização da memória no Estado Moderno}

Dissertação apresentada como requisito parcial para obtenção do título de Mestre pelo Programa de PósGraduação em Relações Internacionais do Instituto de Relações Internacionais da PUC-Rio. Aprovada pela Comissão Examinadora abaixo assinada.

Prof. Paulo Luiz Lavigne Moreaux Esteves

Orientador

Departamento de Relações Internacionais - PUC-Rio

Profa. Marta Regina Fernández y Garcia Moreno

Departamento de Relações Internacionais - PUC-Rio

Profa. Renata Barbosa Ferreira

IBMEC

Profa. Mônica Herz

Vice-Decana de Pós-Graduação do Centro de Ciências Sociais - PUC-Rio

Rio de Janeiro, 28 de outubro de 2011. 
Todos os direitos reservados. É proibida a reprodução total ou parcial do trabalho sem autorização da Universidade, da autora e da orientadora.

\section{Sabrina Villenave}

Graduou-se em Comunicação Social com habilitação em Relações Públicas pela Faculdade Helio Alonso em 2005. Tem interesse pelas áreas de Segurança Internacional e Política Internacional.

Ficha Catalográfica

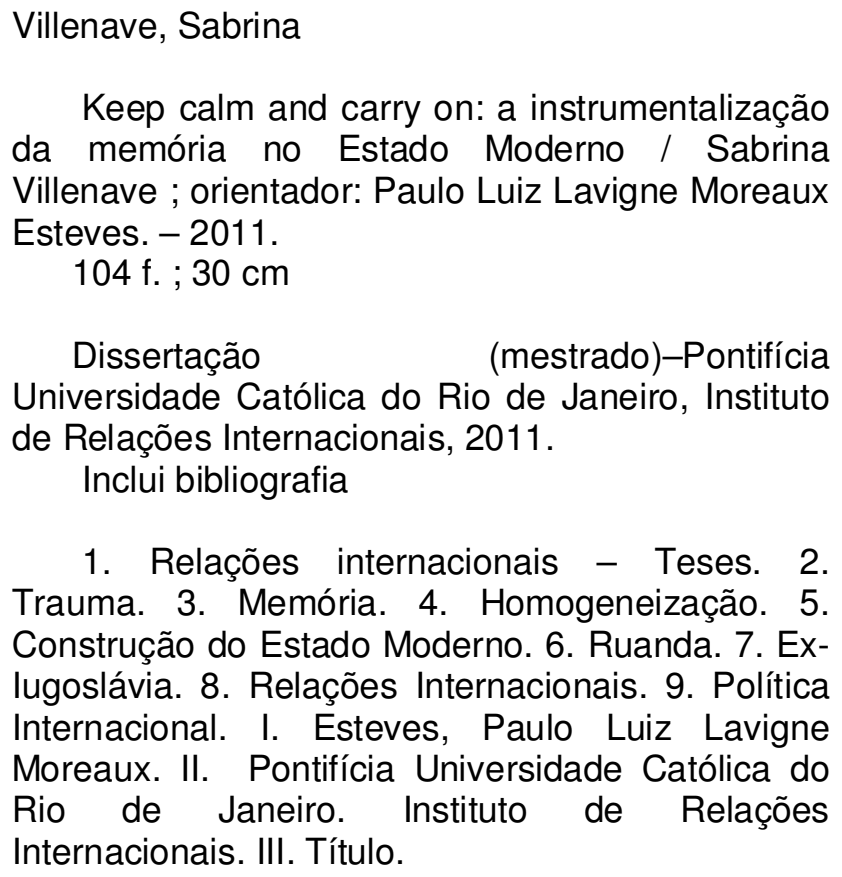

1. Relações internacionais - Teses. 2. Trauma. 3. Memória. 4. Homogeneização. 5. Construção do Estado Moderno. 6. Ruanda. 7. Exlugoslávia. 8. Relações Internacionais. 9. Política Internacional. I. Esteves, Paulo Luiz Lavigne Moreaux. II. Pontifícia Universidade Católica do Rio de Janeiro. Instituto de Relações Internacionais. III. Título.

CDD:327 
A minha mãe por me ensinar que traumas não precisam ser lembrados mesmo que não possam ser esquecidos. Ao meu pai por me mostrar que por mais duro que seja o passado, ele pode ser lúdico. A Maria Leonor Malheiros por me ajudar em ambos os desafios. Amo vocês. 


\section{Agradecimentos}

Ao longo destes dois anos de mestrado, muitas pessoas me incentivaram e compartilharam os momentos contraditórios de angústia e alegria.

Em primeiro lugar, agradeço aos meus pais por apoiarem as minhas escolhas. $\mathrm{O}$ carinho de vocês é sempre fundamental no meu caminhar.

Ao meu irmão pela amizade e momentos alegres. Você me ensina a ver o mundo por uma perspectiva mais leve.

A minha vovó Julia. Sua superação, força de vontade e determinação são exemplos para minha vida.

Aos meus avós Marie-Lyse Helbach, Fathi S.S. Kahil, Jean Villenave e José Damião, que por motivos distintos eu não pude conhecer. Suas histórias e escolhas, que para mim é apenas um mosaico de pequenos azulejos coloridos, são também parte da minha história.

Aos meus amigos de turma, pelo companheirismo nos melhores e nos piores momentos. Com cada um de vocês eu tenho algo especial que foi compartilhado e vivido.

As minhas amigas irmãs, Dani, Quel e Day. Daniela Melina, obrigada pelas opiniões e leitura atenta de meus capítulos. Raquel Sciammarella e Dayana Sciammarella, obrigada pela motivação contagiante, pelo apoio constante e por sempre acreditarem em mim. O carinho e apoio de vocês foram e são fundamentais.

Em especial agradeço à Tânia Mara por me fazer acreditar que montanhas podem vir até nós. À Layla Dawood, Maíra Siman, Natália Félix e Emília Barreto, pela amizade e pelas longas conversas ao longo do mestrado. 
A Erica Simone Resende por me incentivar sempre e por acreditar na importância do tema do trauma e da memória nas Relações Internacionais. Erica, você me apresentou um mundo de possibilidades.

Agradeço profundamente ao meu orientador, Paulo Esteves. Obrigada por confiar em minha capacidade, me incentivar a encontrar alternativas durante o longo caminho de pesquisa e me apoiar desde quando esta dissertação era um esboço de projeto. Sem dúvidas, as suas críticas e sugestões contribuíram muito para meu amadurecimento acadêmico. Para mim, você é um grande exemplo.

Ao professor Luis Fernandes, pela atenção que dispensa a seus alunos e pelos valiosos comentários feitos ao projeto deste trabalho durante nossas aulas de Projeto de Dissertação.

Ao professor Naeem Inayatulah pelo constante incentivo. Naeem, you helped me to find my own voice between so many voices!

Aos professores Didier Bigo e Elspeth Guild por me ajudarem a realizar o sonho antigo de estudar na SciencesPo. Ao Centro de Intercâmbio Acadêmico da PUCRio por realizarem este trabalho tão valioso. Aos professores Ariel Colonomos, Christopher Kutz e Kora Andrieu da SciencesPo pelos valiosos comentários aos primeiros esboços que antes era esta dissertação.

À PUC-Rio, pelo auxílio concedido, sem o qual este trabalho não poderia ter sido realizado. 


\section{Resumo}

Villenave, Sabrina; Lavigne Esteves, Paulo (Orientador). Keep Calm and Carry On: a instrumentalização da memória no Estado Moderno. Rio de Janeiro, 2011. 104p. Dissertação de Mestrado - Instituto de Relações Internacionais, Pontifícia Universidade Católica do Rio de Janeiro.

Uma característica comum ao Estado Moderno é um passado de conflitos e violência. A relação entre esta violência e, muitas vezes, o trauma que decorre dela, irá determinar como será articulada a relação com a memória/esquecimento no momento após os conflitos. Falar de memória não é apenas falar sobre o passado. Falar em memória é também falar do presente e das articulações que resultaram neste presente. Tendo como exemplos a Ex-Iugoslavia e Ruanda é possível se perceber como o Estado Moderno atua através de práticas de memória na monumentalização, na educação e ao trazer uma confrontação com o passado para a construção de uma sociedade homogênea.

\section{Palavras-chave}

Trauma; Memória; Homogeneização; Construção do Estado Moderno; Ruanda; Ex-Iugoslávia; Relações Internacionais; Política Internacional. 


\section{Abstract}

Villenave, Sabrina; Esteves, Lavigne Paulo (Advisor). Keep Calm and carry on: the instrumentalization of memory in the modern state. Rio de Janeiro, 2011. 104p. MSc. Dissertation - Instituto de Relações Internacionais, Pontifícia Universidade Católica do Rio de Janeiro.

A common feature of the modern state is a past of conflict and violence. The relationship between this violence and, often, the trauma that follows it, will determine how the relationship of remembering/forgetting is going to act in the moment after the conflict. Talking about memory is not just to talk about the past. Talking about memory is also to talk about the present. Taking as examples the Former Yugoslavia and Rwanda it is possible to analyze how the modern state acts through the memory practices at monumentalization, education and practices of confrontation with the past for the construction of a homogeneous society.

\section{Keywords}

Trauma; Memory; Homogenization; Modern State Building; Rwanda; Former-Yugoslavia; International Relations; International Politics. 


\section{Sumário}

1 Introdução

2 Trauma, memória e política 17

2.1 O trauma e o Estado Moderno 18

2.1.1 Memória nas resoluções espaciais 20

2.2 Memória, verdade e saber 23

$\begin{array}{ll}2.3 \text { A prática do testemunho } & 28\end{array}$

3 Práticas de memória 33

3.1 Lembrar/Esquecer 34

3.2 Memória como prática 40

3.2.1 Memória de violência 44

3.2.1.1 O Cenotaph 46

3.2.1.2 O Muro do Vietnam 47

3.2.2 Memórias do Holocausto 50

3.3 Memórias contestadas $\quad 55$

3.3.1 Os Contra Monumentos 55

3.3.2 A mobilização dos testemunhos $\quad 57$

$\begin{array}{ll}3.4 \text { Conclusão } & 60\end{array}$

4 A Mobilização das memórias 62

4.1.1 Ex-lugoslávia 63

$\begin{array}{ll}\text { 4.1.2 Ruanda } & 66\end{array}$

4.2 A Mobilização da memória para o conflito 68

4.2.1 Ex-lugoslávia $\quad 69$

$\begin{array}{ll}4.2 .1 .1 \text { Sérvia } & 71\end{array}$

4.2.1.2 Croácia 73

$\begin{array}{ll}4.2 .2 \text { Ruanda } & 75\end{array}$

4.3 A Mobilização da memória na reconstrução 78

$\begin{array}{ll}\text { 4.3.1 O dispositivo das Escolas } & 79\end{array}$

4.3.1.1 Ex-lugoslávia 80 
4.3.1.2 Ruanda $\quad 80$

4.3.2 Monumentos e comemoração 81

4.3.2.1 Ex- lugoslávia 82

4.3.2.1.1 Sérvia 82

4.3.2.1.2 Croácia 83

4.3.2.1.3 Macedônia 84

4.3.2.2 Ruanda 84

4.3.3 Confrontando o Passado $\quad 87$

4.3.3.1 Ex- lugoslávia 88

$\begin{array}{ll}\text { 4.3.3.2 Ruanda } & 90\end{array}$

$\begin{array}{ll}4.4 \text { Conclusão } & 93\end{array}$

5 Conclusão 95

6 Referências Bibliográficas 102 


\section{Siglas e Abreviaturas}

CONADEP - Comissão Nacional para os Desaparecidos

CVR - Comissões de Verdade e Reconciliação

EUA - Estados Unidos da América

PTSD - Pos Traumatic Stress Disorder ou Estresse Pós Traumático

ONU - Organização das Nações Unidas

TPI - Tribunal Penal Internacional

TPIY - Tribunal Penal Internacional para a Ex-Iugoslávia

TPIR - Tribunal Penal Internacional para Ruanda 